\title{
INTRAVENOUS MEDICATION ADMINISTRATION ERRORS AND THIS CAN ENDANGER THE LIVES OF PATIENTS
}

\author{
OMAR ABDULWAHID SALIH AL-ANI* \\ Department of Clinical Pharmacy, Faculty of Pharmacy, Al-Rafidain University College, Baghdad, Iraq. Email: omralani1987@gmail.com
}

Received: 27 February 2020, Revised and Accepted: 21 May 2020

ABSTRACT

Objective: Intravenous errors are one of the most frequent and common medical errors, but no direct causes found. The theory of human error is the most common expression of errors in hospitals, and this can endanger the lives of patients. This research study aims to identify the errors in the vein and try to find solutions to avoid those errors where the study conducted on a sample of hospitals in Baghdad.

Methods: The study conducted to improve health quality in some hospitals. During the study period, a group of severe cases was detected, which based on intravenous infusions. Patients' data and information were collected through five sources, examined and documented venous errors found and placed in a standard classification according to an incorrect dose and incorrect medication. The incorrect dose includes the following: Overdose, extra dose, underdose, wrong strength, and wrong form.

Results: During the period of study, a total of 99 cases, among these cases, 52 incorrect medications include (drug-drug interaction, drug-disease interaction, and not indicated medication) the incorrect dose 42 and route of administration and incorrect rate also take place in mistakes.

Conclusion: Intravenous errors can cause significant harm to patients and health-care providers, so proper attention paid to them. Several reasons may cause medication errors such as lack of experience and knowledge of health-care providers, inaccurate communications that do not explain the drug, and the exact dose. The prescribing errors in the medication or dosage were collected, discussed, and clarified so that the risks arising from them observed so that health-care providers and hospital specialists would be alerted and the study would serve as an alarm for health organizations.

Keywords: Intravenous errors, Wrong dose, Wrong medication, Healthcare, Baghdad.

(C) 2020 The Authors. Published by Innovare Academic Sciences Pvt Ltd. This is an open access article under the CC BY license (http://creativecommons. org/licenses/by/4. 0/) DOI: http://dx.doi.org/10.22159/ajpcr.2020.v13i7.37287

\section{INTRODUCTION}

For medications to have a positive effect on patients and to meet their therapeutic purposes, they must take correctly. Furthermore, any wrong use of the drug leads to serious health problems. There are several stages until the drug reaches the patient starting from the description, preparation, dispensing, and administration of the error that can occur in these stages [1]. Drug errors rank seventh in terms of causes of death [2]

According to the NCC MERP "The National Coordinating Council for Medication Error Reporting and Prevention," the definition of medication error was it is an event that may cause harm to the patient or inappropriate medication use as the management of the drug is in the will of the professional healthcare and patient. Medication errors may be associated with a variety of causes such as health-care products, professional practice, procedures, prescription, and dispensing errors in labeling, composition, packaging, product labeling, distribution, monitoring and use, and lack experience and education for health-care practitioners [3]. Medication errors defined as any error that occurs while prescribing, dispensing, or administering the drug, regardless of whether this error causes harm to the patient or not [4].

Medication errors remain errors and causes of harm to the patient regardless of whether they occur due to negligence, omissions, or lack of education and experience. The majority of countries in the world suffer from medication errors, but these mistakes are increasing in developing countries. Therefore, medication errors are among the most severe health problems in the world, especially if they are for patients suffering from severe and complex medical diseases. The policy of dealing and reducing medication errors is not widespread in the Middle East [5]. There are large quantities and many names for drugs, including identical or similar names in the way of writing, so the handwriting of the prescription is about one-third of the total medication errors. Many drugs have similar names, leading to confusion, and medication errors [6]. For example, miconazole gel is used to treat oral fungi in infants 4 months and older. However, there is another, miconazole is a topical cream for dermatitis and fungi in diapers or cortical allergies in children. This similarity causes much damage to the patient, so it must be clarified.

Mistakes may fall under the general knowledge or rules of the drug as certain medications may not be suitable for some diseases due to an allergy to one of its components or its incompatibility with other medications taken by the patient. Rules-based errors are divided into not applying a good rule (applying a bad rule) such as using overdoses of medication or misapplying a good rule such as injecting medications in an incorrect place. Drug errors can be classified according to the timing or place of occurrence (at any stage of administration of the drug in terms of description, dispensing, or administration) [7].

\section{Classification of medication errors}

The general rule for preventing any error is to understand the causes that lead to that error. Therefore, classifying medication errors, according to some criteria, were very important. Classification systems can be conditional, contextual, or psychological. The conditional classification depends on the examination of the processes in which the error occurred and estimated the conditional probabilities for them. The contextual classification depends on the time, place, people, and medication involved in the drug administration process. The psychological classification depends on the human and the extent of the description of the event (medication error) [8]. Often the medication errors are classified according to the onset, severity, and index of a medication error, underlying cause, and psychological approach [9]. 
The NCC MERP, "The National Coordinating Council for Medication Error Reporting and Prevention," adopted the Medication Error Index based on the severity of its associated outcome in July 1996. It is expected that this indicator contributes to the verification of many health-care practitioners of drug errors and systematically track them. This indicator depends on the factors that are the fault of the patient, the harm to the patient, and the severity of the harm. The council urges health-care providers, suppliers, and researchers to use the index to track medication errors [10].

\section{SUBJECTS AND METHODS}

The study was conducted from October 2018 to February 2019 in Baghdad, Iraq to improve the quality of healthcare. During the study period, a group of severe cases was detected, which based on intravenous infusions. Patients' data and information were collected through five hospitals (Baghdad Teaching Hospital, Iraqi Red Crescent Society, Saint Raphael (Al Rahibat) Hospital, Al-Elwiya Teaching Hospital, and Al-Yarmook Teaching Hospital), examined and documented venous errors found and placed in a standard classification according to an incorrect dose and incorrect medication. The incorrect dose includes the following: Overdose, extra dose, underdose, wrong strength, and wrong form.

All intravenous medications given to patients were monitored in a total of 99 cases. Data collected for each IV infusion case through verity sources are:

- Direct observation

- Responsible for medication administration to the patient

- The record of medication administration

- Medical chart of the patient.

Descriptive statistics are used to describe the basic features of the data in a study. They provide simple summaries about the sample and the measures. Together with simple graphics analysis, they form the basis of virtually every quantitative analysis of data (Table 1).

Pearson correlation coefficient shows the validity which expresses the degree to which a measurement measures what it purports to measure. These validity tests are categorized into two broad components, namely, internal and external validities. Internal validity refers to how accurately the measures obtained from the research were quantifying what it was designed to measure whereas external validity refers to how accurately the measures obtained from the study sample described the reference population from which the study sample was drawn (Tables 2 and 3).

\section{RESULTS}

During the period of study, a total of 99 cases, among these cases, 52 incorrect medications include (drug-drug interaction, drug-disease interaction, and not indicated medication) the incorrect dose 42 and route of administration and incorrect rate also take place in mistake as shown in (Tables 4 and 5).

\section{DISCUSSION}

The study showed that IV errors had a severe consequence that may lead to severe permanent damage and death, (Table 6); most of these errors associated with nurse staff also doctors pharmacists have their place in these errors.

Intravenous pumps cause many medication errors. The most frequent errors were patient identification, orders, documentation, and labeling. Unexpectedly, errors in the rate of deviation were less frequent. Some researchers adopt the IV pump error as an error due to programming [11].

The process of administration of the drug consists of several stages from the first doctor prescribed the drug and then to the pharmacist, where the review and dispensing the drug and then prepare the dose by the nurse to the patient [12].

The wrong medication was the most common errors in the study, followed by an incorrect dose and then an incorrect route of administration and, finally, an incorrect rate. In another study, the data were counterproductive, with the most common errors being dose errors followed by incorrect medication and then incorrect route [13].

Antibiotic has a higher percentage of IV errors, especially ceftriaxone. Ceftriaxone causes anaphylaxis reaction in patients who have an allergy to the cephalosporin group, 34 cases of ceftriaxone IV errors detected during the period of study. Twenty cases were anaphylaxis reaction to the ceftriaxone; the error was given a drug without test patients to allergy for these antibiotic groups. Ceftriaxone when given with ringer solution lead to calcium salt precipitation these condition considered life threating usually occurs with chilled given ringer solution flowed by ceftriaxone by same (micro drip set) these type of mistake reported with 12 cases. Furthermore, two cases show local tissue damage and bleeding at the site of injection; the error has injected the drug in an artery instead of the vein.

On the other hand, we know that DM one of the broadest separated diseases in Iraq and we documented 16 cases of this disease in

Table 1: Descriptive the difference between the samples collected

\begin{tabular}{|c|c|c|c|c|c|c|c|c|}
\hline \multirow[t]{2}{*}{ Drugs } & \multirow[t]{2}{*}{$\mathbf{n}$} & \multirow[t]{2}{*}{ Mean } & \multirow{2}{*}{$\begin{array}{l}\text { Std. } \\
\text { Deviation }\end{array}$} & \multirow[t]{2}{*}{ Std. Error } & \multicolumn{2}{|c|}{$95 \%$ Confidence interval for mean } & \multirow[t]{2}{*}{ Minimum } & \multirow[t]{2}{*}{ Maximum } \\
\hline & & & & & Lower bound & Upper bound & & \\
\hline Ceftriaxone & 34 & 1.0588 & 0.23883 & 0.04096 & 0.9755 & 1.1422 & 1.00 & 2.00 \\
\hline NSAID & 4 & 2.0000 & 0.00000 & 0.0000 & 2.0000 & 2.0000 & 2.00 & 2.00 \\
\hline IV fluid & 4 & 2.0000 & 0.00000 & 0.0000 & 2.0000 & 2.0000 & 2.00 & 2.00 \\
\hline Epinephrine & 2 & 2.0000 & 0.00000 & 0.00000 & 2.0000 & 2.0000 & 2.00 & 2.00 \\
\hline Hydrocortisone & 2 & 2.0000 & 0.00000 & 0.00000 & 2.0000 & 2.0000 & 2.00 & 2.00 \\
\hline Salbutamol & 1 & 2.0000 & . & . & . & . & 2.00 & 2.00 \\
\hline Heparin & 3 & 2.0000 & 0.00000 & 0.00000 & 2.0000 & 2.0000 & 2.00 & 2.00 \\
\hline Nitroglycerine & 5 & 2.0000 & 0.00000 & 0.00000 & 2.0000 & 2.0000 & 2.00 & 2.00 \\
\hline Vancomycin & 1 & 2.0000 & . & . & . & . & 2.00 & 2.00 \\
\hline Doxorubicin & 1 & 2.0000 & . & . & . & . & 2.00 & 2.00 \\
\hline Furosemide & 9 & 2.0000 & 0.00000 & 0.00000 & 2.0000 & 2.0000 & 2.00 & 2.00 \\
\hline Metoprolol & 7 & 2.0000 & 0.00000 & 0.00000 & 2.0000 & 2.0000 & 2.00 & 2.00 \\
\hline Digoxin & 5 & 2.0000 & 0.00000 & 0.00000 & 2.0000 & 2.0000 & 2.00 & 2.00 \\
\hline Alteplase & 1 & 2.0000 & . & . & . & . & 2.00 & 2.00 \\
\hline Diltiazem & 2 & 2.0000 & 0.00000 & 0.00000 & 2.0000 & 2.0000 & 2.00 & 2.00 \\
\hline Total & 99 & 1.5253 & 0.50190 & 0.05044 & 1.4251 & 1.6254 & 1.00 & 2.00 \\
\hline
\end{tabular}


our study, 14 case was an overdose or inappropriate dose of given insulin to treat patient-administered to the ER with hyperglycemia due to uncontrolled diabetic the wrong dose in some case induce hypoglycemia, in Al-Kadhimiya Teaching Hospital female administered with kidney failure and she had diabetic the correct dose of insulin given to the patient by intravenous. However, she shows sweating and dizziness (sing of hypoglycemia), the hypoglycemia occurs due to the damage of kidneys that responsible of metabolism and execration of insulin, also hypokalemia reported after, given iv insulin to ER patients that have hyperglycemia, hypokalemia occurs due to the effect of insulin that increases cellular uptake of potassium, these patient need electrolyte monitoring.

We noted four cases of NASIDs iv errors reported, two of these cases show bleeding during the course of iv diclofenac sodium, the incomplete history from a patient that has peptic ulcer lead to use contraindicated drug for these patients, also chilled show bronchoconstriction after administered to the ER with fracture and given a repeated dose of sodium diclofenac in iv solution, chilled had a history of asthma that makes drug induce the bronchoconstriction. Hypertension also reported after given NASID through a vein to the elderly; the patient has uncontrolled hypertension.

IV fluid (normal saline, and ringer lactate) three cases reported with hypertension and edema in child and two elderly due to fluid overload. Most elderly have decreased renal function due to an increase in age, chronic diseases such as hypertension and DM, and benign prostatic hyperplasia that lead to a decrease in urine output, which makes them more prone to fluid overload in children due to immature kidney function.

IV corticosteroid inpatient with DM reported with hyperglycemia due to the direct effect of cortisone to promote glucose synthesis in

Table 2: Comparison of basic parameters according to their scientific specializing

\begin{tabular}{|c|c|c|c|c|c|}
\hline ANOVA & $\begin{array}{l}\text { Sum of } \\
\text { squares }\end{array}$ & df & $\begin{array}{l}\text { Mean } \\
\text { square }\end{array}$ & $\mathbf{F}$ & Sig. \\
\hline \multicolumn{6}{|l|}{ Incorrect } \\
\hline $\begin{array}{l}\text { Between } \\
\text { groups }\end{array}$ & 21.867 & 16 & 1.367 & 39.743 & .000 \\
\hline $\begin{array}{l}\text { Within } \\
\text { groups }\end{array}$ & 2.820 & 82 & 0.034 & & \\
\hline Total & 24.687 & 98 & & & \\
\hline
\end{tabular}

Table 3: Correlation between parameters

\begin{tabular}{lll}
\hline Correlations & Incorrect & Drugs \\
\hline $\begin{array}{l}\text { Incorrect } \\
\quad \text { Pearson correlation }\end{array}$ & 1 & \\
Sig. (two-tailed) & & $0.787\left(^{* *}\right)$ \\
n & 99 & 9900 \\
Drugs & & \\
$\quad$ Pearson correlation & $0.787\left(^{* *}\right)$ & 1 \\
Sig. (two-tailed) & 0.000 & 99 \\
n & 99 & 99 \\
\hline
\end{tabular}

${ }^{* *}$ Correlation is significant at the 0.01 level (two-tailed)

Table 4: Type of error with no. of case during study

\begin{tabular}{ll}
\hline Errors types & No. of case \\
\hline Incorrect medication (not indicated) & 22 \\
(Drug-drug interaction) & 14 \\
(Drug-disease interaction) & 16 \\
Incorrect dose & 42 \\
Route of administration & 5 \\
Incorrect rate & 2 \\
\hline
\end{tabular}

the liver and decrease insulin sensitivity that leads to increase blood glucose level, also these cases seen in female patients with gestational diabetic how to receive IV steroid before doing premature labor. One case reported in the ER for a child had severe bronchial contraction doctors prescribe salbutamol. However, by a mistake, the nurse gives salbutamol directly through the IV line instead of giving him in the nebulizer; the patient develops severe tachycardia this due to betaagonist activity of salbutamol on the heart which leads increase heart rate, but the bronchial contraction subsides due to beta-agonist activity on the lung. Three cases of heparin reported with inappropriate dose develop bleeding. One of the most drug use in ER nitroglycerin inpatient with angina that already administrated to the ER and nitroglycerine chewable during arrival, so when nitroglycerine administered IV, they develop hypotension and many cases reported with migraine exacerbation.

Table 5: Drugs reported with IV error and no. of cases

\begin{tabular}{ll}
\hline Drug & No. of case \\
\hline Ceftriaxone & 34 \\
Insulin & 16 \\
NASID & 4 \\
IV fluid & 4 \\
Epinephrine & 2 \\
Cortisone & 2 \\
Salbutamol & 1 \\
Heparin & 3 \\
Nitroglycerin & 5 \\
Vancomycin & 1 \\
Doxorubicin & 1 \\
Furosemide & 9 \\
Metoprolol & 7 \\
Digoxin & 5 \\
Alteplase & 1 \\
Hydromorphone & 2 \\
Diltiazem & 2 \\
\hline
\end{tabular}

NASIDs: Nonsteroidal anti-inflammatory drugs

Table 6: Consequence of drug errors with number of cases

\begin{tabular}{lll}
\hline Drugs & Consequence & No. of cases \\
\hline Ceftriaxone & Anaphylaxis reaction & 20 \\
& Precipitation & 12 \\
Insulin & Tissue damage & 2 \\
& Hypoglycemia & 11 \\
NSAID & Hypokalemia & 5 \\
& Bleeding & 2 \\
IV fluid & Hypertension & 1 \\
& Broncho constriction & 1 \\
Epinephrine & Hypertension & 1 \\
& Edema & 3 \\
Hydrocortisone & Myocardia infraction & 1 \\
Salbutamol & Difficult breathing & 1 \\
Heparin & Hyperglycemia & 2 \\
Nitroglycerine & Arrhythmia & 1 \\
& Bleeding & 3 \\
Vancomycin & Hypotension & 4 \\
Doxorubicin & Migraine & 1 \\
Furosemide & Extravasation & 1 \\
& Extravasation & 1 \\
Metoprolol & Hypotension & 4 \\
Digoxin & Electrolyte disturbance & 4 \\
Alteplase & Kidney damage & 1 \\
Hydromorphone & Arrhythmia & 7 \\
Diltiazem & Arterial fibrillation & 5 \\
\hline Hens: Central & Bleeding & 1 \\
& Cypotension & 1 \\
& Arrhythmia & 2 \\
\hline
\end{tabular}

CNS: Central nervous system 
One case in Baghdad medical city child 13 years old has acute leukemia vancomycin one of the drugs prescribed to a child when iv vancomycin is given to the child develop erythema with swelling due to incorrect insertion of IV line to the soft-tissue instead of a vein (Fig. 1)

Extravasation and necrosis also reported in elderly patient at the oncology department of Baghdad medical city after receiving IV doxorubicin the drug given way incorrectly due to the wrong insertion of IV line into the soft-tissue instead of the vein (Fig. 2).

IV furosemide widely uses in hospital especially in the ER for many cases, the mistakes occur due to high dose of diuretic that leads to renal damage; also heavy use of diuretic (furosemide) lead to decrease tubular reabsorption of electrolyte, and this will lead to increase their execration into the urine this will lead to electrolyte imbalance especially $\mathrm{K}$ and this will lead to arrhythmia, hypotension also has been reported in some cases of using IV furosemide.

IV metoprolol induces arrhythmia in many cases, especially in the patient with prolonging QT syndrome and the elderly with the sick sinus syndrome. Atrial fibrillation has been reported in a patient with heart failure with cardiogenic shock receiving IV digoxin.

The patient admitted to the ER with acute myocardial infarction. After giving alteplase, the patient develops bleeding because of bariatric surgery 2 weeks ago; alteplase should not be given during the first 3 weeks after surgery. The wrong was inappropriate history taking.

Hydromorphone has to give to the patient with severe pain, and chronic use of antidepressant this will result in CNS depression effect and decrease in respiratory effort, another patient on antihypertensive drugs show hypotension after receiving IV hydromorphone both of cases the wrong way due to inappropriate history taking from the patient. Diltiazem induces hypotension in a patient with a history of hypotension and already take the antihypertension drug before admission to the ER.

\section{CONCLUSION}

Intravenous medications occur with a wide range of medication errors that may cause harm to the patient. The causes of these errors are inaccurate communication, lack of experience, inadequate knowledge, and poor performance of health-care practitioners. Health-care practitioners must contribute to identifying those errors so that information can be used to reduce errors. Through this study, we explained that prescribing errors are the most prevalent, then management errors and finally monitoring errors. These errors cause severe damage to health-care providers and patients. They may lead to the death of the patient, so be careful and try to avoid them. It has been noted in the past that reports of drug errors have increased significantly. A new technology-based methodology must be developed to manage these errors in an excellent way to minimize them. It is noteworthy that the number of errors will be reduced if health-care practitioners behave more responsibly toward the patient and use safety nets and appropriate procedures to deal with intravenous medicines and how to manage them to avoid making errors.

\section{RECOMMENDATIONS}

Through this study and review of the literature, we have come up with some recommendations that reduce the errors of the drug and include:

- It is possible to use many strategies to achieve safety and safety for patients and try to avoid errors, including strategies such as barcode technology and the use of electronic prescription drug and careful use of electronic pumps

- Put the patient under direct observation before and after administering the dose

- Identify risk factors that cause many mistakes and include: Lack of experience, an overload of nurses, lack of equipment, lack of staff, and lack of use of technology

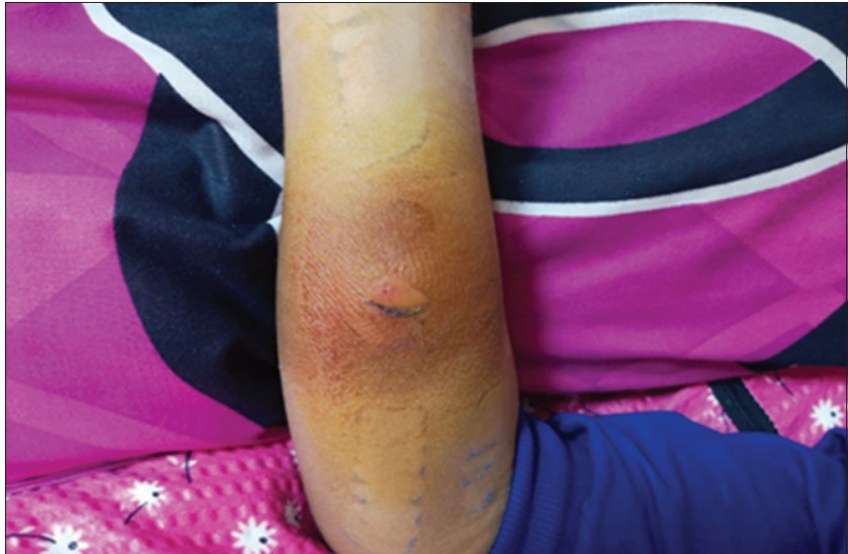

Fig. 1: Show swollen of arm cause of extravasation

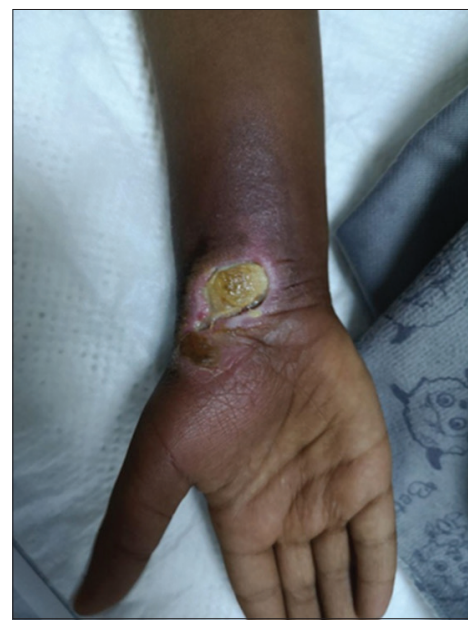

Fig. 2: Show lesion cause of doxorubicin extravasation

- Develop specific strategies to manage the stage of preparation of the drug due to severe errors.

\section{ACKNOWLEDGMENT}

The author thanks Pharmacist Sajjad Younis and pharmacist Mohamed Taha for collecting information and following up with hospitals.

\section{AUTHORS' CONTRIBUTIONS}

The author declares that this work was done by the author named in this article.

\section{CONFLICTS OF INTEREST}

The author declares that they have no conflicts of interest.

\section{REFERENCES}

1. Cohen MR. Medication Errors. $2^{\text {nd }}$ ed. Washington, DC: Wash, American Pharmacists Association; 2007.

2. Moyen E, Camiré E, Stelfox HT. Clinical review: Medication errors in critical care. Crit Care 2008;12:208.

3. National Coordinating Council for Medication Error Reporting and Prevention. Available from: http://www.nccmerp.org/councilRecs. html. [Last accessed on 2010 Apr 07].

4. Ferner RE, Aronson JK. Errors in Prescribing, Preparing and Giving Medicines: Definition, Classification and Prevention. Available from: http://www.hero.org.ph/files/pharmacovigilance.pdf. [Last accessed on 2010 May 07].

5. Alsulami Z, Conroy S, Choonara I. Medication errors in the Middle East countries: A systematic review of the literature. Eur J Clin Pharmacol 
2013;69:995-1008.

6. Anacelto TA, Perini E, Rosa MB, Cesar CC. Drug dispensing errors in the hospital pharmacy. Clinics (Sao Paulo) 2007;62:243-50.

7. Williams DJ. Medication errors. J R Coll Physicians Edinb 2007;37:343-6.

8. Aronson JK. Medication errors: Definitions and classification. Br J Clin Pharmacol 2009;67:599-604.

9. Štrbová P. Lékové chyby v ošetrovatelství. Klin Farmakol Farm 2013;27:37-40.

10. Cousins DD, Heath WM. The national coordinating council for medication error reporting and prevention: Promoting patient safety and quality through innovation and leadership. Jt Comm J Qual Patient
Saf 2008;34:700-2.

11. Eskew JA, Jacobi J, Buss WF, Warhurst HM, DeBord CL. Using innovative technologies to set new safety standards for the infusion of intravenous medications. Hosp Pharm 2002;37:1179-89.

12. Gladstone J. Drug administration errors: A study into the factors underlying the occurrence and reporting of drug errors in a district general hospital. J Adv Nurs1995;22:628-37.

13. Jerry P, Sammie B, Allen B, Carol H, Peter H, Laureen YL, et al. Retrospective analysis of mortalities associated with medication errors. Am J Health Syst Pharm 2001;158:1835-41. 